\title{
PERCEPÇÃO DE GRADUANDOS DIANTE DO CONTATO COM A MATA DE TABULEIRO E O MANGUEZAL: PRIMEIRAS IMPRESSÕES
}

\author{
Matheus Oliveira Fortaleza ${ }^{1}$ \\ André Ferreira Porfírio² \\ Isabel Cristina Higino Santana ${ }^{3}$ \\ Cristina de Almeida Rocha-Barreira ${ }^{4}$
}

Resumo: A pesquisa avaliou a percepção de alunos de graduação que visitaram uma trilha ecológica com ecossistemas mata de tabuleiro e manguezal. A análise se deu através de um questionário aplicado após a realização da trilha guiada por monitores, avaliando temas como impactos ambientais, conservação e a relação humana com a natureza. Os visitantes destacaram que na mata de tabuleiro a flora lhes chamou mais atenção, e no manguezal a fauna; demonstraram saber a importância de conservar os ambientes e avaliaram positivamente a visita. Assim, a trilha foi considerada uma ótima ferramenta para a promoção ao público conhecimento e um maior contato com diferentes ecossistemas.

Palavras-chave: Trilhas Ecológica; Percepção; Educação Ambiental; Manguezal; Mata de Tabuleiro. 


\section{Introdução}

O atual modo de vida em que as sociedades estão inseridas, baseado em práticas não sustentáveis, está diretamente atrelado às degradações e ao domínio humano sobre a natureza, gerando de forma progressiva desequilíbrios ambientais. Narcizo (2009) já relatava em produções científicas a questão depreciativa do ambiente natural por conta da revolução industrial e tecnológica, destacando a ação predatória do homem.

A revolução industrial e tecnológica dos últimos tempos levou o ambiente a um estado de depreciação nunca visto anteriormente. Antropocêntrico e ganancioso, o homem acreditou poder tirar o máximo proveito dos recursos naturais do planeta, sem sofrer as consequências de seus atos (NARCIZO, 2009, p. 87).

Para Villar et al. (2008), uma das grandes dificuldades para a proteção do meio ambiente está nas diferenças de percepções dos valores e da importância dos mesmos entre os indivíduos de culturas diferentes ou de grupos socioeconômicos que desempenham funções distintas.

Conviver em espaços que integram a natureza e o homem é um dos preceitos de harmonia em sociedade. Nesse sentido, a escola como espaço de formação e conscientização pode ser um desses modelos de entendimento articulado com a Educação Ambiental (EA).

Embora a EA se constitua em um campo contestado, na perspectiva de Maknamara (2009), a sua ampla diversidade com enfoque nos aspectos teóricos e metodológicos permite estimular nos indivíduos uma consciência e assim, contribuir para "o desenvolvimento de ações produtoras de subjetividades mais solidárias dos seres humanos entre si e com os outros seres" (GUIMARÃES, 2003). Assim, compreender aspectos que se relacionem, se torna relevante para a construção de uma postura mais consciente quanto à manutenção da biodiversidade.

A EA, enquanto instrumento gerador de mudança de atitudes, tem a finalidade de preparar o indivíduo e a sociedade para realizar ações de desenvolvimento sustentável, em resposta aos desafios do mundo globalizado (DIAS, 2004). Pode também ser definida como a incorporação de critérios socioambientais, ecológicos, éticos e estéticos, nos objetivos didáticos da educação (MEDINA, 2003).

Na perspectiva da educação, Paim e Borges-Nojosa (2014) afirmam que documentos legais obrigam o enfoque da Educação Ambiental no ensino, desde a educação básica até o ensino superior, no entanto, entendem que nos moldes apresentados, como um tema transversal, na prática, as ações quando ocorrem são pontuais.

Enquanto instrumento de ensino e aprendizagem, e para além dessas questões, como ferramenta de sensibilização e conscientização para Marcatto (2002), por meio da Educação Ambiental é possível dialogar sobre os problemas ambientais que hoje nos cercam. Nesse percurso, espera-se 
alcançar as pessoas e sensibilizá-las para as questões ambientais relacionadas à biodiversidade.

Esse caminhar pode acontecer através do ensino, sendo ele, formal e informal onde os sujeitos envolvidos, estudantes e professores, todos os outros segmentos da população, em coletividade se tornem replicadores das informações e conhecimentos que conscientizem sobre a necessidade de preservar os ambientes.

Essa tomada de consciência, entendemos como a percepção ambiental do homem quanto ao ambiente que o cerca, ou seja, o ato de perceber o ambiente no qual está inserido, aprendendo a proteger e a cuidar do mesmo (FAGGIONATO, 2005). A EA pode ainda ser utilizada para proporcionar melhores experiências de integração aos ambientes naturais. Juntamente com a educação, podem ser importantes na defesa do meio ambiente, contribuindo na reaproximação do homem com a natureza bem como na sensibilização referente à conservação.

Na visão de Marczwski,

para a maior relevância e significado do aprendizado e para o estabelecimento de uma consciência ambiental mais efetiva, é fundamental que os alunos compreendam o meio ambiente prioritária e inicialmente a partir de suas próprias experiências e realidades" (MARCZWSKI, 2006, p.15).

Nesse sentido, estabelecer o sentimento de pertencimento a um lugar pode contribuir para essa tomada de consciência. Conforme Machado (1996), isso pode acontecer quando homem e ambiente se tornam familiar e consequentemente carregado de afetividade. É onde Relph (1979) acredita que o homem expressa suas emoções e sentimentos "suas identidades, intenções, responsabilidades, interações".

Outrossim, a EA deve estar inclusa desde a formação básica aos cursos de graduação, abordando uma problemática que correlacione aspectos sociais, ecológicos, econômicos, políticos, culturais, científicos, tecnológicos e éticos para a formação de pessoas interessadas e engajadas com a causa ambiental. De acordo com Barros; Dines (2000), os visitantes de áreas verdes que apresentam maior escolaridade, normalmente são mais conscientes e receptivos com relação às necessidades de conservação ambiental e das atratividades ecoturísticas e, casos orientados podem apresentar alto grau de comprometimento para a conservação destes ambientes.

Novas abordagens educacionais vêm sendo propostas, tendo como foco a EA, entre elas, para o desenvolvimento do ecoturismo (CAMPOS; FILLETO 2011, COELHO 2011, SANTOS 2011), como para o ensino formal (GONZÁLES-GAUDIANO; LORENZETTI 2009). Uma dessas propostas 
destaca o uso das trilhas ecológicas como espaços de conscientização e de EA.

Dessa maneira, tais espaços podem ser bastante utilizados como importantes ferramentas pedagógicas de EA, possibilitando que em áreas naturais sejam criadas verdadeiras salas de aulas ao ar livre e verdadeiros laboratórios vivos, promovendo interesse, curiosidade, sobretudo proporcionando formas variadas de aprendizado tradicional, incentivando a preservação ambiental (SILVESTRE; PESSOA; SILVA, 2008).

O ecossistema manguezal é restrito aos litorais tropicais, geralmente associado à desembocadura de rios e sob a influência das variações de maré. Nestes ambientes, predominam espécies vegetais distintas, que se associam a outros componentes animais (BRANCO, 1988; ODUM, 1988; SCHAEFFERNOVELLI, 2004). A mata de tabuleiro é um ecossistema típico na zona costeira do Ceará, apresentando características de uma savana arbórea aberta, semelhante ao Cerrado, com árvores de baixo porte e várias gramíneas, uma fauna bastante diversificada tanto de invertebrados como de vertebrados (PRATES et al. 1981; SEMACE, 2017).

Devido o manguezal e a mata de tabuleiro serem susceptíveis às ações eco pedagógicas no contexto da EA, estes proporcionam, através da observação, o reconhecimento de espécies no ambiente natural e suas relações com os demais seres vivos (FARRAPEIRA; PINTO, 2005). Desta forma, o presente estudo buscou avaliar a importância da visitação às trilhas ecológicas nesses dois ecossistemas, considerando as principais características e pontos potenciais para a observação da fauna e flora, a percepção do público sobre as questões ambientais, destacando temas como impactos, importância da conservação e modo como as pessoas pensam e avaliam a sua relação com a natureza, em especial as matas de tabuleiro e os manguezais.

\section{Material e Métodos}

Buscando avaliar a importância das trilhas ecológicas como espaços de formação para uma consciência ambiental, esta pesquisa classificada como pesquisa de campo, utilizou como percurso metodológico a abordagem quantitativa combinada com uma análise qualitativa (APPOLINÁRIO, 2006). A escolha pela abordagem mista ou pesquisa quali-quantitativa se deu pelo fato de ambas, além de apresentarem potencialidades e limitações, podem ser utilizadas com propósitos distintos e que tal "vantagem de integração consiste em retirar o melhor de cada uma para responder uma questão específica" (PARANHOS et al., 2006, p.389).

A trilha ecológica escolhida para a realização da pesquisa se encontra demarcada em uma área de 4,4 ha (Figura 1), com demarcação na área do Centro de Estudos Aquáticos Costeiros (CEAC) do Instituto de Ciências do Mar da Universidade Federal do Ceará (UFC), localizado às margens do estuário do

revista brasileira educação ambiental 
rio Pacoti, município do Eusébio, Ceará. Tal escolha de área se deu devido as atividades previstas e desenvolvidas pelo projeto de extensão da UFC intitulado "Trilhas Ecológicas do Estuário do Rio Pacoti: observando a biota do manguezal", que está inserido no Programa de Educação Ambiental Marinha do Instituto de Ciências do Mar (PEAM), também localizado no espaço do CEAC.

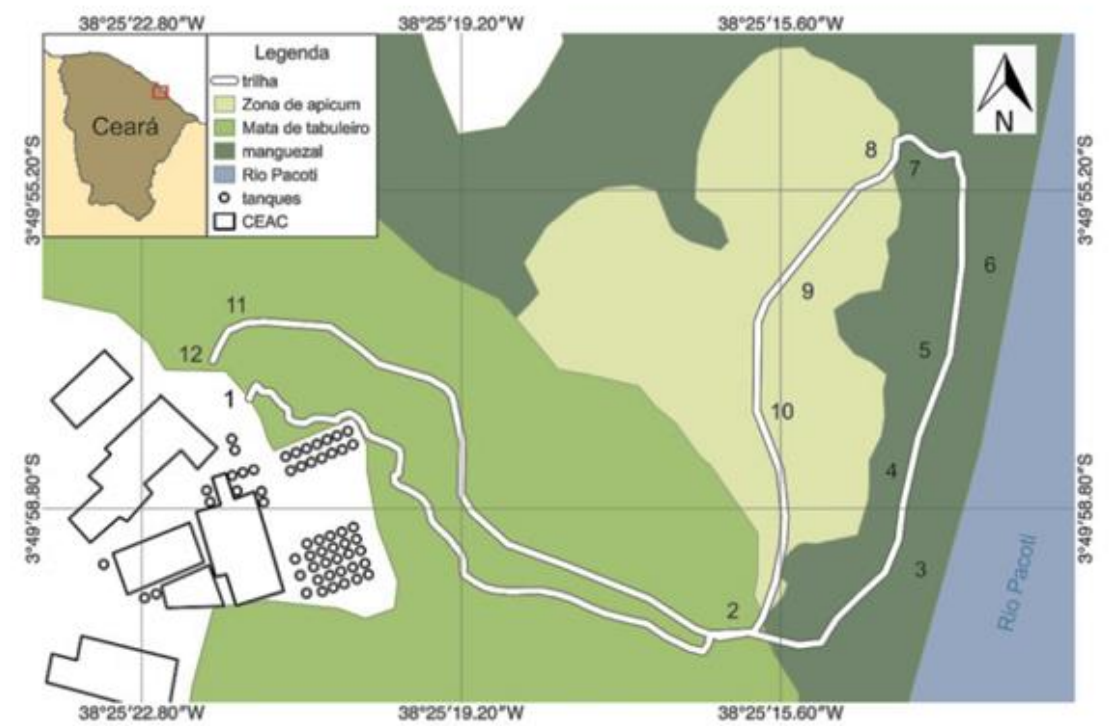

Figura 1: Mapa da trilha ecológica do estuário do Rio Pacoti, localizada no Centro de Aquicultura Costeira (CEAC), Eusébio CE. Fonte: Jadson Pinto de Lima (2016)

Neste centro de pesquisa, além da área construída, existem ainda uma área de vegetação de tabuleiro, apicum, uma faixa de mangue e uma vasta planície flúvio-marinha, o que favorece, na maré baixa, caminhadas e observações da elevada riqueza de invertebrados, peixes e aves.

Para a divulgação do projeto, convites foram feitos por meio de informes em salas de aula de diferentes cursos de graduação da UFC e pelas redes sociais do PEAM (@teriopacoti, @peam_ufc). Posteriormente, foram agendadas turmas de alunos para participarem das visitas.

O período de realização das visitas ocorreu durante os meses de abril e setembro de 2017, nos horários de 8:00 e 14:00 h, o percurso durava em torno de 2 horas. Os participantes foram selecionados em função do destacado interesse manifestado em visitar a área, alguns já tendo desenvolvidos atividades diversas relacionadas ao meio ambiente.

As turmas de visitantes formadas constituíram grupos de caminhadas que foram acompanhados por no mínimo um monitor do projeto. Durante o percurso da trilha, os visitantes receberam explicações sobre as características da mata de tabuleiro e do manguezal, ressaltando-se diferenças entre os habitats $e$ as principais características ambientais que influenciam na Revbea, São Paulo, V. 14, № 2: 30-46, 2019. 
biodiversidade da área. Outro aspecto ressaltado durante a caminhada foram os impactos ambientais presentes no percurso.

Ao final de cada visita à trilha, os alunos de cursos de graduação foram convidados a responder um questionário de avaliação da atividade de campo presencial, o qual abordou questões relacionadas à relevância das informações fornecidas durante a trilha, a experiência e sensações de conhecer estes ambientes e as percepções sobre a conservação dos ecossistemas. A elaboração do questionário foi realizada a partir da análise da literatura especializada sobre o tema em estudo, além de adaptações de questionários já utilizados nos estudos de Bezerra, Feliciano e Alves (2008).

Assim, nesta pesquisa, o referido instrumento foi elaborado de forma semiestruturada, apresentando 10 perguntas com possibilidades de respostas fechadas (múltipla escolha), onde as mesmas podiam ser elencadas como: sim ou não, e ainda, sendo possível a escolha de mais de um item. Em 7 perguntas foi permitido aos respondentes detalharem sua resposta, portanto, tratando de perguntas com respostas abertas, com justificativa ou comentário. O percentual das respostas foi definido considerando o total de participantes que as escolheram.

As perguntas foram formuladas de maneira a identificar o tipo de motivação que levou os visitantes a realizar a trilha, além de compreender suas percepções quanto às diferenças de habitats, principais espécies avistadas, relevância das informações fornecidas, sensações ao observar elementos da fauna, compreensão sobre a conservação dos diferentes ecossistemas: (matas de tabuleiro e manguezal) e dos impactos ambientais encontrados.

A estatística descritiva foi utilizada para demonstrar, por meio de tabelas e gráficos, os dados da pesquisa de modo que se pudesse obter uma visão geral dos resultados. Assim, as respostas foram tabuladas em planilhas no programa Microsoft Excel 2016 e analisadas qualitativamente (forma descritiva) e quantitativamente (em porcentagem). A interpretação dos resultados foi organizada por categorias e temas, os comparando quanto às semelhanças apresentadas pelas respostas (REIGOTA, 2001).

Esse procedimento metodológico pretendeu utilizar-se da vivência, da análise do meio e do cotidiano dos visitantes para a compreensão de seus saberes e percepções acerca do ambiente e da atividade.

\section{Resultados e discussão}

\section{Caracterização dos respondentes}

Durante a pesquisa, foram recebidas 5 turmas de alunos de cursos de graduação distintos, totalizando 63 visitantes que responderam o questionário referente a percepção ambiental. A priori os dados revelam que entre os cursos representados durante a trilha se destacam os cursos Ciências ambientais (40\%), Ciências Biológicas (30\%), e Zootecnia (17,5\%) com a maior participação de alunos da Universidade Federal do Ceará. O percentual

revista brasileira educação ambiental 
restante se distribui de forma mais reduzida entre os cursos identificados na (tabela 1). O maior interesse manifestado por alunos destes cursos reforça a afirmação de Cerciná et al, (2009), ao destacarem um maior conhecimento a respeito do assunto por parte de alunos dos cursos de graduação em biologia e áreas afins, devido a um maior contato desses estudantes com as questões ambientais. Sobral (2014), que também aborda essa questão, entende que

Estudantes universitários nos dias atuais, fazem parte de um grupo social que tem a sua disposição uma grande cobertura de informações a respeito de questões ambientais, principalmente pela comunicação em massa, mais ampla que a geração anterior (SOBRAL, 2014, p.22).

Tabela 1: Quantidade de alunos que visitaram a Trilha Ecológica do estuário do rio Pacoti e seus respectivos cursos de graduação.

\begin{tabular}{lcc}
\hline \multicolumn{1}{c}{ Curso } & $\begin{array}{c}\text { No de } \\
\text { Visitantes }\end{array}$ & $\begin{array}{c}\text { Porcentagem } \\
(\%)\end{array}$ \\
\hline $\begin{array}{l}\text { Ciências } \\
\text { Ambientais/UFC }\end{array}$ & 25 & $40 \%$ \\
Ciências Biológicas/UFC & 19 & $30 \%$ \\
e UECE & 11 & $17,5 \%$ \\
Zootecnia/UFC & 2 & $3 \%$ \\
Direito/UFC & 2 & $3 \%$ \\
Agronomia/UFC & 1 & $1,6 \%$ \\
Ecologia/UFERSA & 1 & $1,6 \%$ \\
Medicina & 1 & $1,6 \%$ \\
Veterinária/UECE & 1 & \\
Biotecnologia/UFC & Fon & \\
\hline
\end{tabular}

Fonte: Autores (2017)

A idade dos visitantes variou de 18 a 46 anos, com uma média de 21 anos, o que destaca o interesse e a participação do público jovem em atividades de campo. Este resultado assemelha-se ao observado por Souza e Martos (2008), que atribuíram esse fato devido a esse público em particular buscar atividades ao ar livre em ambientes naturais.

Esse aspecto de interagir com os espaços e ecossistemas de forma mais livre, permite compreender o estudo da percepção ambiental de uma determinada comunidade, pois segundo Marczwski (2006), esse instrumento é bastante eficaz para apreensão dos comportamentos vigorantes, configurandose também nesse sentido, na elaboração de planos e ações que proporcionem e valorizem atitudes conscientes de sensibilização para tomada de atitudes éticas e responsáveis em relação ao meio e a biodiversidade. 
Tabela 2: Questões e respostas referentes a percepção ambiental dos visitantes da trilha ecológica do estuário do Rio Pacoti, localizada no Centro de Aquicultura Costeira (CEAC), Eusébio CE. (Percentual de respostas referente ao total de escolha do item pelos visitantes).

\begin{tabular}{|c|c|c|c|c|c|c|c|c|c|}
\hline \multirow{3}{*}{$\begin{array}{l}\text { Questões } \\
\text { Q1 . Você já conhecia a trilha ecológica do } \\
\text { Estuário do rio Pacoti? }\end{array}$} & \multicolumn{9}{|c|}{ Respostas (\%) } \\
\hline & Sim & Não & & & & & & & \\
\hline & $66 \%$ & $34 \%$ & & & & & & & \\
\hline \multirow{2}{*}{$\begin{array}{l}\text { Q2. O que atraiu a sua atenção ao } \\
\text { percorrer a área da mata de tabuleiro? }\end{array}$} & Animais & Plantas & \multicolumn{2}{|c|}{ Impactos Ambientais } & Nada & Outro & & & \\
\hline & $46 \%$ & $62 \%$ & \multicolumn{2}{|c|}{$38 \%$} & $3 \%$ & $2 \%$ & & & \\
\hline \multirow{2}{*}{$\begin{array}{l}\text { Q3. O que atraiu a sua atenção ao } \\
\text { percorrer a área do manguezal? }\end{array}$} & Animais & Plantas & Rio Pacoti & \multirow{2}{*}{\multicolumn{2}{|c|}{$\begin{array}{l}\text { Impactos Ambientais } \\
30 \% \\
\end{array}$}} & Nada & Outro & & \\
\hline & $73 \%$ & $52 \%$ & $41 \%$ & & & & & & \\
\hline \multirow{2}{*}{ Q4. Que animais você viu no manguezal? } & Caranguejo & Pássaro & Caracol & Peixe & Sapo & Outro & Lagarto & Cobra 1 & Nenhum \\
\hline & $100 \%$ & $62 \%$ & $37 \%$ & $24 \%$ & $21 \%$ & $10 \%$ & $6 \%$ & $0 \%$ & $0 \%$ \\
\hline \multirow{2}{*}{$\begin{array}{l}\text { Q5. Qual foi a sua sensação ao observar } \\
\text { estes organismos? }\end{array}$} & Admiração & Curiosidade & Indiferença & Medo & Surpresa & & & & \\
\hline & $79,00 \%$ & $42,00 \%$ & $1,50 \%$ & $1,50 \%$ & $0 \%$ & & & & \\
\hline \multirow{2}{*}{$\begin{array}{l}\text { Q6. Observou alguma alteração causada } \\
\text { pela atividade humana ao ambiente? }\end{array}$} & Sim & Não & & & & & & & \\
\hline & $98,40 \%$ & $1,60 \%$ & & & & & & & \\
\hline \multirow{2}{*}{$\begin{array}{l}\text { Q7. Se sim, quais alterações você } \\
\text { observou? }\end{array}$} & Lixo & Caça/Pesca & Corte na Mata & Barulhos & Queimadas & Construç & ões & & \\
\hline & $92 \%$ & $60 \%$ & $48 \%$ & $19 \%$ & $13 \%$ & $11 \%$ & & & \\
\hline \multirow{2}{*}{$\begin{array}{l}\text { Q8. Você acha importante conservar os } \\
\text { Ecossistemas: Mata de Tabuleiro e } \\
\text { Manguezal ? }\end{array}$} & \multicolumn{2}{|c|}{ Sim, é muito importante } & \multicolumn{2}{|c|}{ Não, não é importante } & \multicolumn{2}{|c|}{$\begin{array}{l}\text { Não é importante se não } \\
\text { houver ganho de dinheiro }\end{array}$} & \multicolumn{3}{|c|}{$\begin{array}{l}\text { Sim, é importante, mas } \\
\text { não tudo }\end{array}$} \\
\hline & \multicolumn{2}{|c|}{$98,40 \%$} & \multicolumn{2}{|l|}{$0 \%$} & \multicolumn{2}{|c|}{$0 \%$} & & $1,50 \%$ & \\
\hline \multirow{2}{*}{$\begin{array}{l}\text { Q9. A Trilha é uma alternativa para } \\
\text { desenvolver atividades de educação } \\
\text { ambiental? }\end{array}$} & \multirow{2}{*}{\multicolumn{2}{|c|}{$\begin{array}{c}\text { Sim, mas não forma } \\
\text { consciência ambiental } \\
3 \%\end{array}$}} & \multirow{2}{*}{\multicolumn{2}{|c|}{$\begin{array}{c}\text { Sim, porque é importante } \\
\text { preservar } \\
97 \% \\
\end{array}$}} & \multirow{2}{*}{\multicolumn{2}{|c|}{$\begin{array}{c}\text { Não, a atividade não } \\
\text { desperta a reflexão } \\
0 \%\end{array}$}} & & & \\
\hline & & & & & & & & & \\
\hline \multirow{2}{*}{$\begin{array}{l}\text { Q10. Atribua uma nota para as atividades } \\
\text { desenvolvidas durante a sua visita }\end{array}$} & Boa & Excelente & Ruim & Péssima & & & & & \\
\hline & $57,10 \%$ & $42,90 \%$ & $0 \%$ & $0 \%$ & & & & & \\
\hline
\end{tabular}

Fonte: Autores (2018).

Conforme a Tabela 2, a trilha ecológica já era conhecida para 66,6\% dos respondentes, dos quais 55,5\% já conheciam, por terem em outro momento, participado de aulas de campo (diferentes disciplinas de seus cursos) na mesma área demarcada. $O$ fato de cerca da metade dos respondentes já terem conhecido a trilha evidencia o interesse de retornar, numa perspectiva de aprender e vivenciar mais experiências no local. Segundo Kellert; Wilson (1995), saídas a campo que aproximam os estudantes ao naturalismo é uma alternativa para o aumento da afinidade pelo ambiente natural.

Para Catabriga e Moreira (2016),

O campo é um excelente ambiente de estudo para as disciplinas envolvidas no trabalho, proporcionando um ensino de qualidade para uma aprendizagem significativa no processo de ensino-aprendizagem. A ligação de temas relevantes ao meio ambiente deve transcender a sala de aula, levando o aluno a reconstruir ideias, valores e significados, aumentando, assim, o seu interesse pela disciplina de Ciências e provocando o aprendizado desejado (CATABRIGA; MOREIRA,2016, p.7).

É um instrumento que possibilita a aproximação da realidade, um enfrentamento em relação às questões e impactos ambientais vivenciadas 
pelos participantes da pesquisa. Enquanto ferramenta didática pode contribuir no desenvolvimento de uma postura de reflexão, crítica e contextualização, favorecendo a construção do conhecimento.

\section{O que viram ao longo da caminhada: Observações ao longo da trilha}

$\mathrm{Na}$ área que delimita o trecho inicial da trilha, representada por uma mata de tabuleiro, as diferentes espécies de plantas foi o que mais chamou a atenção para $61,9 \%$ dos respondentes, seguido das espécies de animais $46 \%$ e dos impactos ambientais $38 \%$. Para dois participantes (3\%), nada atraiu a atenção, e um participante $(1,5 \%)$ incluiu uma observação de que o solo da mata Ihe chamou atenção devido à presença de "ferro" (óxido de ferro, comum em sedimentos terrígenos costeiros no Ceará) (Figura 2).

80

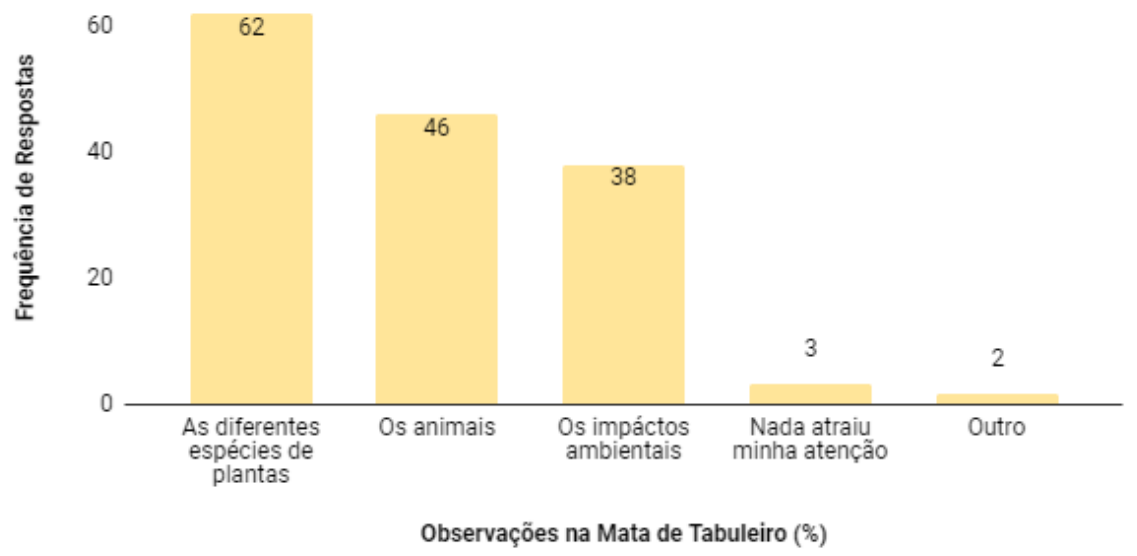

Figura 2: Frequência de respostas referentes às observações que chamaram a atenção dos visitantes no ecossistema de Mata de Tabuleiro. Fonte: Autores (2017).

No manguezal o que mais atraiu a atenção dos visitantes, diferentemente da mata de tabuleiro, foram os animais, que representaram a maior frequência de respostas $73 \%$, seguindo das plantas $52 \%$, do próprio rio Pacoti $41 \%$ e dos impactos ambientais 30\% (Figura 3). 
80

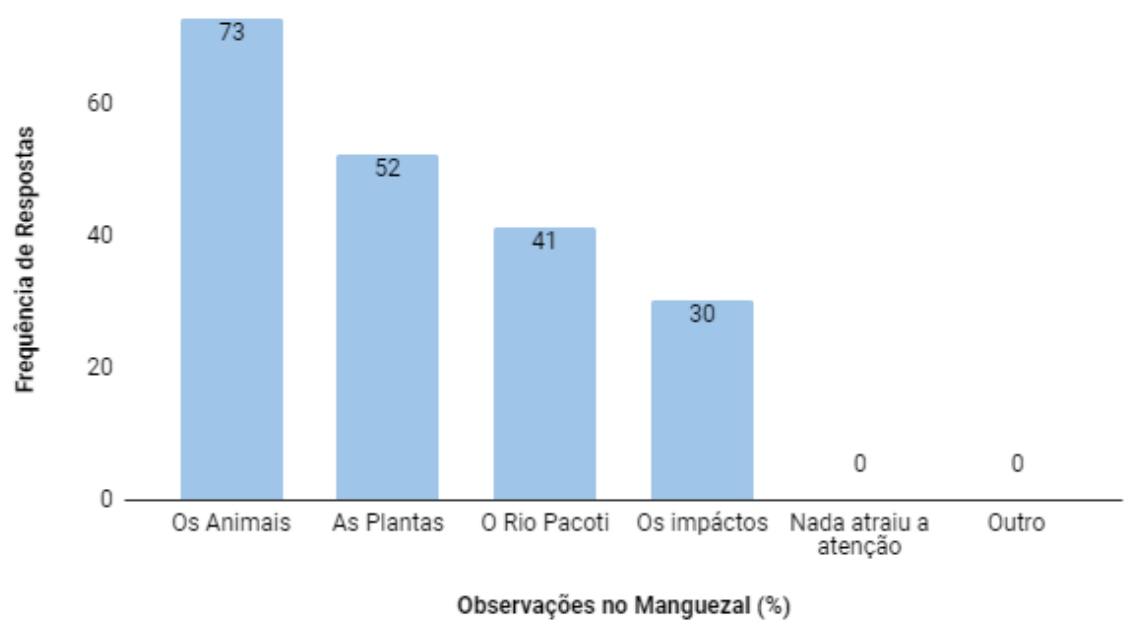

Figura 3: Frequência de respostas referentes às observações que chamaram atenção no ecossistema de Manguezal. Fonte: Autores (2017).

Na mata de tabuleiro, devido a maior riqueza de espécies vegetais, era de se esperar que as plantas fossem o motivo que mais chamaria a atenção do dos visitantes, no entanto, o que se verificou foi um número elevado de respostas destacando a visualização de animais. Tal aspecto é relevante, pois é difícil a avistar animais neste trecho do percurso, entretanto os visitantes perceberam os sons de pássaros e visualizaram as tocas de mamíferos e muitos insetos.

Os impactos ambientais (área desmatada e zonas erodidas) também foram evidenciados nesse trecho do percurso, sendo um fator negativo que chamou a atenção dos visitantes. Rodrigues (2008) ressalta que visitas a ambientes impactados, faz com que os alunos enxerguem o ecossistema com novo olhar, promovendo uma consciência ecológica. A visita in lócus permite um olhar mais sensível às questões, informações e elementos percebidos no meio visitado (RODRIGUES; FARRAPEIRAS, 2008).

Apesar da vegetação do manguezal ter características marcantes, a facilidade de observar uma maior diversidade de fauna neste ambiente justifica os animais serem mais atrativos aos visitantes. Segundo Hanai e Netto (2006), somente por meio da percepção e interpretação ambientais, os visitantes poderão atribuir valores e importâncias diferenciadas para os locais de visitação. Trata-se, pois, das diversas relações estabelecidas entre a sociedade e o meio natural que a cerca. Por meio desse instrumento (que possui um amplo potencial) é possível elencar aspectos negativos e positivos dessa relação constituída entre sociedade e natureza, pois os indivíduos se mostram de diferentes maneiras ao ambiente que se encontram inseridos.

Em todas as visitas, observações quanto à atividade dos caranguejos (escavação de tocas, alimentação, disputa por território e locomoção), foram 
facilmente avistadas, como também, a presença frequente de aves e moluscos (caracol) sobre os troncos e raízes das árvores de mangue.

Devido aos horários da visitação (desfavoráveis à observação de animais com hábitos noturnos ou que evitam exposição à elevadas temperaturas) e aos diferentes impactos na área, em raras ocasiões foram avistados sapos ou lagartos, os quais chamaram a atenção do público quando presentes. A observação de rastros e tocas de mamíferos também foram destacados pelos visitantes. A redução de espécies de animais e vegetais se torna consequência da perda de habitat e das degradações ambientais resultante das atividades humanas (WILSON, 1997). Estas perturbações estão presentes na área da trilha e foram fortemente destacadas pelos visitantes (Figuras 3 e 4). Conforme Oliva Junior (2012), o desrespeito com a natureza e o meio ambiente tem favorecido na tomada de atitudes e ações antrópicas que vem levando no aumento de danos a flora e a fauna em geral.

Nos dias atuais o ser humano busca cada vez mais mecanismos para extrair da natureza seus bens naturais o que na maioria das vezes deixa um rastro impactante no local explorado, buscando atender apenas as suas necessidades sem a preocupação do dano causado ao ambiente. E como o homem já modificou todos os aspectos do seu habitat, utilizamse dos recursos naturais e modificam constantemente 0 ambiente onde vivem, transformando cada vez mais o meio natural (OLIVA JÚNIOR, 2012, p.2).

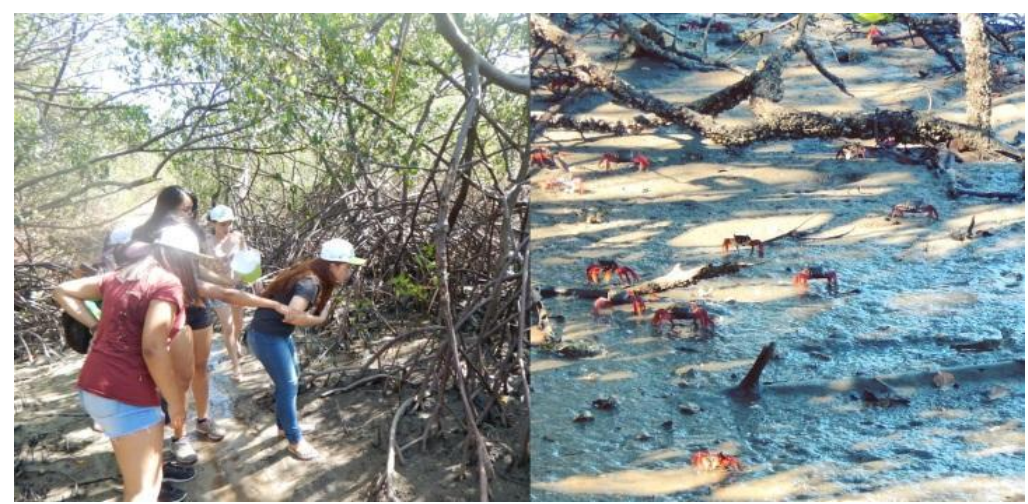

Figura 4: Visitantes observando a fauna do manguezal e caranguejos Aratus (Goniopsis cruentata) em atividade na maré baixa do Rio Pacoti. Fonte: Autores (2017).

Considerando a fauna do manguezal, todos os visitantes (100\%) avistaram caranguejos em atividade, $62 \%$ alguma ave, $37 \%$ viram caracóis, $24 \%$ peixes, $21 \%$ sapos e $10 \%$ relataram ter visto animais não relacionados nas opções do questionário, como uma variedade de invertebrados terrestres (aranha, gafanhoto, lagarta, libélula, mosquito, borboleta), 6\% avistaram lagartos. Apesar do registro de ocorrência, na área da trilha, nenhuma cobra foi vista pelos respondentes (Figura 5). Um visitante também destacou os humanos na lista de outros animais avistados.

Revbea, São Paulo, V. 14, № 2: 30-46, 2019. 


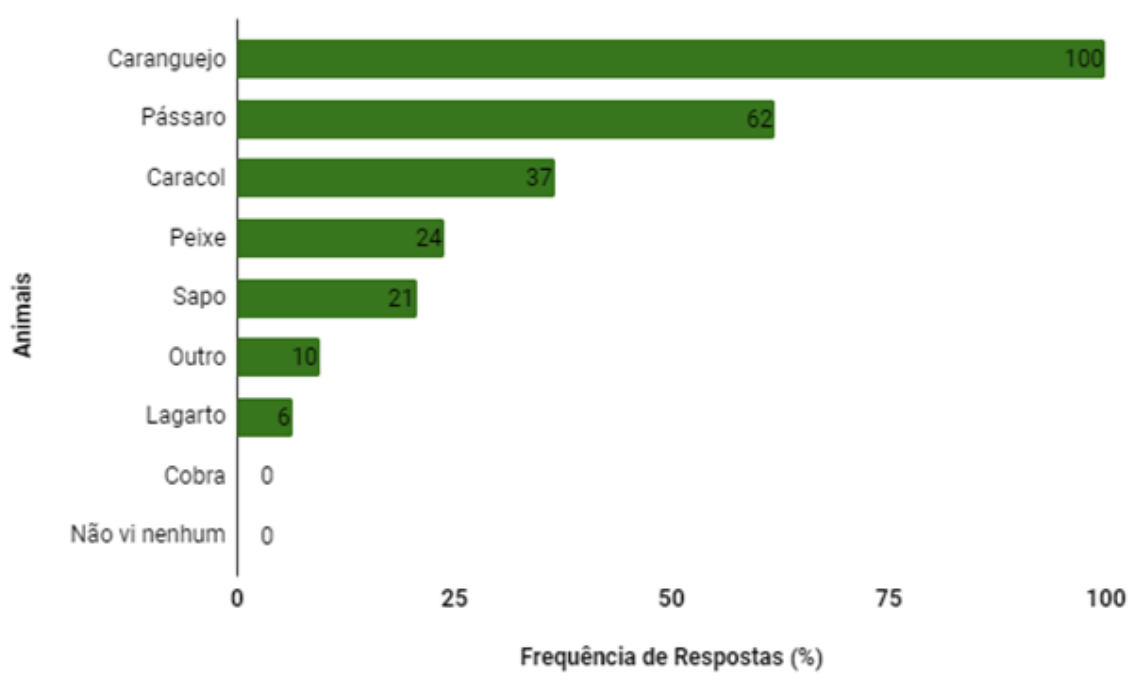

Figura 5: Frequência de respostas referentes aos animais mais observados pelos visitantes na Trilha Ecológica do estuário do rio Pacoti. Fonte: Autores (2017).

Com relação à sensação que os visitantes tiveram ao observar a fauna presente no manguezal, as mais destacadas foram admiração e curiosidade por terem encontrado os animais no seu ambiente natural e demonstraram interesse de saber mais sobre os organismos observados (Figura 6). Nenhuma pessoa ficou surpresa por nunca ter visto aqueles organismos. Apenas um dos respondentes afirmou ter sentido medo e outro relatou indiferença. Experiências práticas de relacionamento dos alunos com animais vivos mostraram que aversão e o medo diminuem conforme a interação aumenta, muitas vezes, dando lugar à afinidade e admiração (KELLERT; WILSON, 1995).

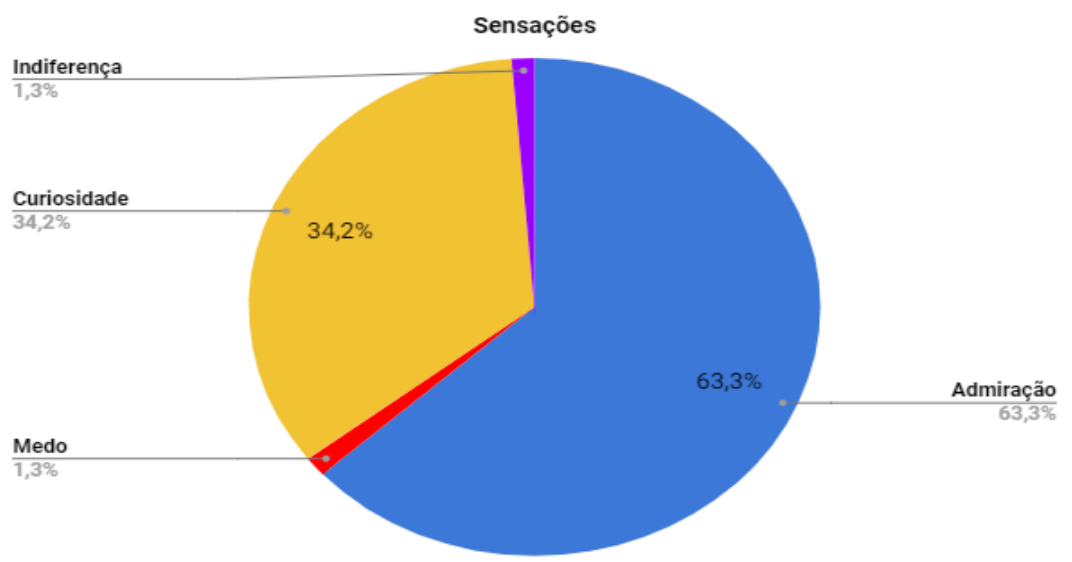

Figura 6: Frequência de respostas dos visitantes que marcaram apenas uma opção referente às sensações que tiveram ao observar a fauna do ecossistema de manguezal.

Fonte: Autores (2017).

Revbea, V. 14, № 2: 30-46, 2019. 
Um dos sentimentos que o ser humano possui por outros animais é a biofilia, a tendência de se associar emocionalmente a eles. O sentimento oposto, a biofobia, reação adversa à presença de outra espécie viva, varia do desconforto ao temor, como na aversão às serpentes (WILSON, 2002), por exemplo. Segundo Seniciato; Cavassan (2004), aulas e atividades de campo que aproximam os alunos dos objetos de estudo da ecologia aumentam o interesse e internalizam o conhecimento sobre o tema.

Para $98,4 \%$ dos respondentes da pesquisa, as alterações causadas pela atividade humana impactam de forma direta no ambiente, fato comprovado pelos mesmos ao longo do percurso da trilha. Para esse grupo percentual, $92 \%$ destacaram o lixo, $60 \%$ a caça e a pesca, $48 \%$ o corte na mata, $19 \%$ o barulho, $12 \%$ as queimadas e $11 \%$ as construções (Figura 7 ).

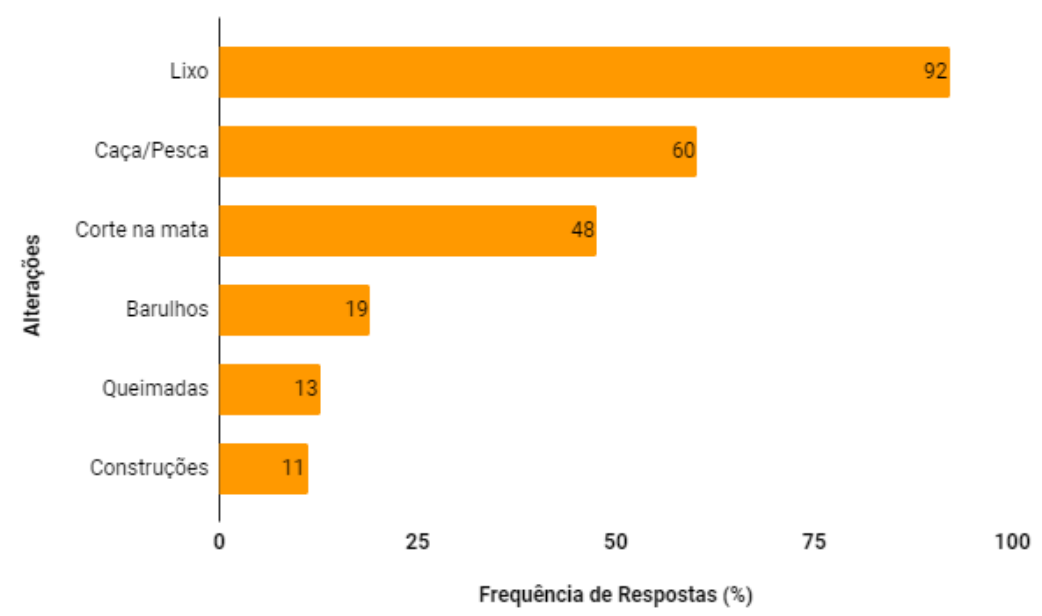

Figura 7: Frequência de respostas referentes às alterações antrópicas presentes na Trilha Ecológica do estuário do rio Pacoti. Fonte: Autores (2017).

Evidenciando que apesar da trilha estar inserida em uma área de proteção ambiental, existe uma série de impactos visíveis causado por pessoas que constantemente frequentam e utilizam o local de forma inadequada. OlivaJúnior; Sousa (2012) destacam que a degradação ambiental provocada pela ação antrópica, deixa rastros impactantes no meio explorado, sendo estes fatos significativamente negativos para uma percepção de um ambiente completamente natural. Por outro lado, observar a realidade de ambientes impactados é relevante na construção de uma consciência ecológica.

\section{Percepções sobre a conservação ambiental}

Quando questionados acerca da importância da conservação dos ecossistemas, 98,4\% responderam que era importante conservar; apenas uma pessoa $(1,5 \%)$ respondeu que era importante, mas não completamente tudo, e justificou que com manejo e gestão era possível explorar os recursos sem prejudicar 0 ambiente. Esse fato pode ser decorrente de todos os visitantes 
serem alunos de graduação e fazerem parte de uma parcela da população que possui maior acesso à informação relacionada à sustentabilidade.

Apesar de nem sempre ocorrer dessa forma, Leonardi (1997) destaca que a universidade tem um papel importante na formação ambiental dos profissionais que está colocando no mercado, necessitando incorporar a dimensão ambiental nos seus objetivos, conteúdos e metodologias.

Ao avaliar se a realização da trilha foi uma boa alternativa para se desenvolver atividades de EA, 97\% responderam que "sim, pois é importante conhecer para preservar" e 3\% responderam que "sim, mas que não contribui para formação da consciência ambiental”. A percepção pela ampla maioria dos visitantes de que a trilha ecológica tem uma importância no que se refere a transmitir conhecimentos de relevância ambiental corrobora com a eficácia da execução dessas atividades no âmbito da Educação Ambiental. Segura (2001) destaca que o conhecimento é essencial tanto para embasar uma leitura crítica da realidade, quanto para buscar instrumentos que solucionem problemas ambientais mais concretos.

Os visitantes atribuíram uma nota para as atividades realizadas na trilha ecológica do estuário do Rio Pacoti. Conforme a resposta de 57,1\%, as atividades foram consideradas boas e $42,8 \%$ consideraram-nas como excelente. A satisfação do público com as atividades desenvolvidas na trilha pode ser atribuída ao fato de o contato com os ambientes naturais proporcionarem uma forma de "fuga" da rotina estressante dos centros urbanos bem como um relaxamento físico e mental (VALLEJO, 2013). No caso dos visitantes considerados neste estudo, esta "fuga" representa a saída de rotina acadêmica cotidiana e pela atividade ser realizada com uma metodologia diferenciada ao abordar conteúdos em campo que geralmente são vistos apenas de maneira teórica em sala de aula.

\section{Conclusões}

A realização da trilha foi uma estratégia pedagógica favorável que se mostrou adequada na construção de uma consciência mais crítica e ambiental acerca do meio e da biodiversidade investigados nesta pesquisa.

Permitiu aos participantes da pesquisa uma aproximação e um maior contato em um ambiente de transição entre os ecossistemas de mata de tabuleiro e manguezal. Levou os respondentes, ao longo das visitas, e através das atividades de EA desenvolvidas, a um enfrentamento sobre a importância da conservação, promovendo com isso, uma reflexão sobre seu papel enquanto indivíduo responsável nesse processo, tornando-se protagonista de ações e atitudes para com o meio ambiente e a biodiversidade.

As observações sobre a percepção dos alunos dos cursos de graduação que participaram do estudo apontaram que as atividades junto à natureza despertam um maior interesse e senso crítico referente às questões ambientais. Por outro lado, mesmo sendo estes visitantes mais esclarecidos 
quanto ao meio ambiente, ainda assim demonstram pouca vivência e conhecimento sobre a estrutura e funcionamento destes ecossistemas. Este fato aponta para necessidade de estimular os professores dos cursos de graduação na área de ciências da natureza a intensificarem as aulas de campo.

O fato de os visitantes avaliados serem alunos de graduação influenciou numa maior compreensão da importância de se conservar os ecossistemas. E o contato com a natureza, juntamente com a transmissão de conhecimento em campo, foram aspectos que levaram o público a avaliar positivamente a trilha.

\section{Agradecimentos}

A todos os monitores e visitantes da trilha que tornaram possível a realização desse trabalho.

\section{Referências}

BARROS, M. I. A; DINES, M. Mínimo impacto em áreas naturais: uma mudança de atitude. In: SERRANO; C. (org) A educação pelas pedras: ecoturismo e Educação Ambiental. São Paulo: Chronos, p. 47-84, 2000.

BEZERRA,T. M. O.; FELICIANO, A. L. P.;ALVES, A.G.C. Percepção ambiental de alunos e professores do entorno da Estação Ecológica de Caetés-Região Metropolitana do Recife-PE. Biotemas, v. 21, n. 1, p. 147-160, 2008.

BRANCO, S. M. O meio ambiente em debate. São Paulo, Editora Moderna, 1988.

CERCINÁ, M. et al. A Percepção Ambiental da Comunidade Universitária e Educação Ambiental no Morro Santana: Unidade de Conservação nos Limites da Universidade. In: Anais do $12^{\circ}$ Encuentro de Geógrafos de América Latina. Montevideo, Uruguay, 2009.

DIAS, G. F. Educação Ambiental: princípios e práticas. 9. ed. São Paulo: Gaia,2004.

FAGGIONATO, S. Percepção ambiental, 2005 Disponível em < http://educar.sc.usp.br. > Acesso em: 26 de jul. 2017.

FARRAPEIRA, C. M. R.; PINTO, S.L. Práticas e metodologias do ensino de Zoologia. Recife: Universidade Federal Rural de Pernambuco. 2005.

HANAI, F.Y.; NETTO, J. P.S. Instalações ecoturísticas em espaços naturais de visitação: meios para propiciar a percepção e a interpretação ambientais. OLAM Ciência \& Tecnologia, Rio Claro, v. 6, n. 2, p. 200-223, dez. 2006. 
OLIVA-JÚNIOR, E. F.; SOUZA, I.S. Os impactos ambientais decorrentes da ação antrópica na nascente do Rio Piauí - Riachão do Dantas/SE. Revista Eletrônica da Faculdade José Augusto Vieira. ANO V, n. 7, p. 17. 2012.

KELLERT, S. R.; WILSON, E.O. (Ed.). The biophilia hypothesis. Island Press, 1995.

LEONARDI, M.L.A. A Educação Ambiental como um dos instrumentos de superação da insustentabilidade da sociedade atual. In: CAVALCANTI, C. (Org.) Meio ambiente, desenvolvimento sustentável e políticas públicas. São Paulo: Cortez, Recife: Fundação Joaquim Nabuco, p. 391-408, 1997.

MEDINA, N. M. Educação Ambiental: uma metodologia participativa de formação. Vozes, 2003.

ODUM, E. P. Ecologia. 8 eds. Rio de Janeiro: Guanabara Koogan, 1988. 434 p PRATES, D. W.; L. C. S. Gatto; M. I. P. Costa. 1981. Geomorfologia - Projeto RADAMBRASIL, Levantamento dos recursos naturais. Rio de Janeiro, Ministério de Minas e Energia, v. 23. p. 301-348.

REIGOTA, M.A.S. et al. Ecoando ressonâncias da Educação Ambiental: descobertas, conflitos, diálogos; por uma ecologia sonora sensível. ERAS: European Review of Artistic Studies, v. 2, n. 1, p. 64-83, 2011.

RODRIGUES, L.L.; FARRAPEIRA, C.M.R. Percepção e Educação Ambiental sobre o ecossistema manguezal incrementando as disciplinas de ciências e biologia em escola pública do Recife-PE. Investigações em Ensino de Ciências, v. 13, n. 1, p. 79-93, 2008.

SCHAEFFER-NOVELLI, Y.; COELHO J, C.; TOGNELLA-DE-ROSA, M. Manguezais. São Paulo: Ática, 2004.

SEGURA, D.S.B. Educação Ambiental na escola pública: da curiosidade ingênua à consciência crítica. Annablume, 2001.

SEMACE. Área de Proteção Ambiental do Rio Pacoti. Disponível em: $<$ http://www.semace.ce.gov.br/2010/12/area-de-protecao-ambiental-do-riopacoti/>. Acesso em: 20/11/2017

SENICIATO, T.; CAVASSAN, O. Aulas de campo em ambientes naturais e aprendizagem em ciências: um estudo com alunos do ensino fundamental. Ciência \& Educação (Bauru), p. 133-147, 2004.

SILVESTRE, D. O; PESSOA, B. G. S; SILVA, L. M. T. A ecoeducação no vale do rio Gramame em João Pessoa, PB: a trilha ecológica da escola viva olho do tempo. In: Anais do II Simpósio de Geografia Física do Nordeste, João Pessoa, PB: Universidade Federal da Paraíba. 2008.

SOUZA, P.C.; LESJAK MARTOS, H. Estudo do uso público e análise ambiental das trilhas em uma unidade de conservação de uso sustentável: Floresta Nacional de Ipanema, Iperó-SP. Revista Árvore, v. 32, n. 1, 2008. 
VALLEJO, L. R. Uso público em áreas protegidas: atores, impactos, diretrizes de planejamento e gestão. Revista Eletrônica Anais Uso Público em Unidades de Conservação, v. 1, n. 1, p. 13-26, 2013.

VILLAR, L. M. et al. A percepção ambiental entre os habitantes da região noroeste do estado do Rio de Janeiro. Escola Anna Nery Revista de Enfermagem, v. 12, n. 2, p. 285-290, 2008.

WILSON, E. O. A situação atual da diversidade biológica: Biodiversidade. Rio de Janeiro: Nova Fronteira, p. 3-24, 1997.

WILSON, E. O. O futuro da vida: um estudo da biosfera para a proteção de todas as espécies, inclusive a humana. Rio de Janeiro: Campus, 2002 